OPEN ACCESS

Edited by:

Mei-Ru Chen,

National Taiwan University, Taiwan

Reviewed by:

Yonggang Pei,

University of Pennsylvania,

United States

Yoshitaka Sato,

Nagoya University, Japan

${ }^{*}$ Correspondence:

Asuka Nanbo

nanboa@med.hokudai.ac.jp

Specialty section:

This article was submitted to

Virology,

a section of the journal

Frontiers in Microbiology

Received: 28 December 2017

Accepted: 27 February 2018

Published: 16 March 2018

Citation:

Nanbo A, Noda T and Ohba Y (2018) Epstein-Barr Virus Acquires Its

Final Envelope on Intracellular

Compartments With Golgi Markers.

Front. Microbiol. 9:454.

doi: 10.3389/fmicb.2018.00454

\section{Epstein-Barr Virus Acquires Its Final Envelope on Intracellular Compartments With Golgi Markers}

\author{
Asuka Nanbo ${ }^{1 *}$, Takeshi Noda² and Yusuke Ohba' \\ 1 Department of Cell Physiology, Faculty of Medicine and Graduate School of Medicine, Hokkaido University, Sapporo, \\ Japan, ${ }^{2}$ Laboratory of Ultrastructural Virology, Institute for Frontier Life and Medical Sciences, Kyoto University, Kyoto, Japan
}

Herpesvirus subfamilies typically acquire their final envelope in various cytoplasmic compartments such as the trans-Golgi network (TGN), and endosomes prior to their secretion into the extracellular space. However, the sites for the final envelopment of Epstein-Barr virus (EBV), a ubiquitous human gamma herpesvirus, are poorly understood. Here, we characterized the sites for the final envelopment of EBV in Burkitt's lymphoma cell lines induced into the lytic cycle by crosslinking cell surface lgG. Electron microscopy revealed the various stages of maturation and egress of progeny virions including mature EBV in irregular cytoplasmic vesicles. Immunofluorescence staining showed that gp350/220, the major EBV glycoprotein, and the viral capsid antigen, p18, efficiently colocalized with a cis-Golgi marker, GM130. gp350/220 partly colocalized with the TGN, which was distributed in a fragmented and dispersed pattern in the cells induced into the lytic cycle. In contrast, limited colocalization was observed between gp350/220 and endosomal markers, such as a multi-vesicular bodies marker, CD63, a recycling endosome marker, Rab11, and a regulatory secretion vesicles marker, Rab27a. Finally, we observed that treatment of cells with brefeldin A, an inhibitor of vesicle trafficking between the endoplasmic reticulum and Golgi apparatus, resulted in the perinuclear accumulation of gp350/220 and inhibition of its distribution to the plasma membrane. Brefeldin A also inhibited the release of infectious EBV. Taken together, our findings support a model in which EBV acquires its final envelope in intracellular compartments containing markers of Golgi apparatus, providing new insights into how EBV matures.

Keywords: Epstein-Barr virus, final envelopment, egress, cis-Golgi, trans-Golgi network

\section{INTRODUCTION}

Epstein-Barr virus (EBV), a ubiquitous human gammaherpesvirus, infects a majority of the population worldwide and establishes a persistent lifelong, mostly asymptomatic infection in them. EBV infection is also associated with various lymphoid and epithelial malignancies such as Burkitt's lymphoma (BL), Hodgkin's disease, gastric carcinoma, and nasopharyngeal carcinoma (Longnecker et al., 2013). In latently infected cells the EBV genome is efficiently maintained extrachromosomally (Yates et al., 1996; Nanbo et al., 2007). Either spontaneously or exogenous induction initiates lytic infection, which leads to several 100 -fold amplification of the viral genome within 1-2 days (Hammerschmidt and Sugden, 1988). Lytic DNA replication produces long concatemers (Bloss and Sugden, 1994), which eventually are cleaved and packaged as linear genome units in capsids. Replication of EBV DNA and its packaging occur in the nucleus. 
Enveloped viruses including herpesvirus acquire host-derived envelope in a variety of intracellular compartments. The three subfamilies of herpesvirus, alphaherpesviruses, betaherpesviruses, and gammaherpesviruses, appear to share a novel mechanism for maturation and egress of virions through several budding and fusion events during replication, which prevents disruption of cellular membranes (Johnson and Baines, 2011; Henaff et al., 2012). This process has been well studied with alphaherpesviruses (Gershon et al., 1994; Zhu et al., 1995; Granzow et al., 1997; Hambleton et al., 2004; Wisner and Johnson, 2004; Sugimoto et al., 2008; Hogue et al., 2014; Buckingham et al., 2016). During a productive infection, viral DNAs are replicated in the nucleus via viral machinery. Synthesized viral DNAs are used as templates for gene transcription, which leads to the synthesis of viral structural proteins to produce capsids. Replicated DNAs are then packaged into capsids in the nucleoplasm. Nucleocapsids acquire an envelope by budding through the inner nuclear membranes (INMs) into the perinuclear space. This process is known as the primary envelopment. Perinuclear enveloped virus particles undergo de-envelopment, which is mediated by membrane fusion between their primary envelope and the outer nuclear membrane (ONM). This process delivers nucleocapsids into the cytoplasm, where they acquire a layer of tegument proteins, which ultimately fills the space between the capsids and the envelopes. These tegument proteins promote the earliest stages of herpesvirus replication, including shutting off of host protein synthesis for alphaherpesviruses and transactivation of early viral genes. Tegument-coated nucleocapsids then undergo a secondary envelopment by budding into cytoplasmic compartments, which produce mature virions in these compartments. This process is defined as the final or secondary envelopment. Vesicles containing mature virions are then transported to the cell surface, where they fuse with the plasma membrane (PM) to release virions into extracellular space. For the alphaherpesviruses including herpes simplex virus (HSV), pseudorabies (PRV), and varicella-zoster virus (VZV), the final envelopment occurs in vesicles derived from the trans-Golgi network (TGN) (Gershon et al., 1994; Zhu et al., 1995; Granzow et al., 1997; Hambleton et al., 2004; Wisner and Johnson, 2004; Sugimoto et al., 2008; Hogue et al., 2014; Buckingham et al., 2016), and the Rab5-positive early endosomes (EE) (Harley et al., 2001).

Betaherpesviruses such as human cytomegalovirus (HCMV), human herpesvirus type 6 (HHV-6), appear to generate unique compartments by reorganizing pre-existing cellular compartments possessing a variety of cellular markers including TGN, EE, multi-vesicular body (MVB), and late endosome (LE) (Tooze et al., 1993; Sanchez et al., 2000; Fraile-Ramos et al., 2002; Homman-Loudiyi et al., 2003; Das et al., 2007; Mori et al., 2008).

In contrast, the mechanisms of maturation and egress of gammaherpesvirus have been poorly characterized.

In some previous studies, electron microscopic analysis visualized the various stages of the life-cycles of EBV (Seigneurin et al., 1977; Greenspan et al., 1989; Lee and Longnecker, 1997; Lake and Hutt-Fletcher, 2000) and of Kaposi sarcoma-associated herpesvirus (KSHV) (Orenstein et al., 1997). Moreover,
Peng et al. (2010) took advantage of electron tomography to characterize the ultrastructural basis of the MHV-68 lifecycle. They showed that tegumented capsids bud into vesicles located adjacent to Golgi apparatus to acquire a final envelope. These findings suggest that EBV shares the mechanism of virion maturation and egress with other herpesvirus subfamilies, however, the sites for its final envelopment have not been demonstrated because of the lack of a fully permissive culture model for the lytic cycle. Some latently EBV-infected BL cell lines can be induced into the lytic cycle with varying efficiency by treatment with chemical inducers, such as phorbol esters, $n$-butyrate, or by ligation of surface immunoglobulin (zur Hausen and Fresen, 1978; Takada, 1984; Faggioni et al., 1986).

Here, we have characterized the sites for the final envelopment of EBV in the Akata BL cell line (Takada et al., 1991; Shimizu et al., 1994; Nanbo et al., 2002, 2012, 2013, 2016) induced into the lytic cycle by crosslinking of surface immunoglobulin. Akata cells are particularly responsive to this treatment, with up to $50 \%$ of cells converting to the lytic form of infection in a synchronous manner.

Our findings demonstrate that the final envelopment of EBV takes place in compartments containing cis-Golgi and TGN characteristics. We also evaluate a mechanism for the maturation and egress of EBV virions based on these findings.

\section{MATERIALS AND METHODS}

\section{Cell Culture}

Epstein-Barr virus-positive African BL-derived Akata (Akata ${ }^{+}$) cells (Takada et al., 1991; Shimizu et al., 1994; Nanbo et al., 2002, 2012, 2013, 2016) were maintained in RPMI-1640 medium containing 10\% fetal bovine serum (FBS) (Sigma-Aldrich, St. Louis, MO, United States) and antibiotics. EBV-negative BL Daudi (Daudi ${ }^{-}$) cells were isolated from EBV-positive clones by the limiting dilution (Klein et al., 1968). Akata- EBV-eGFP cells are latently infected with a recombinant Akata strain EBV encoding eGFP gene inserted into viral BXLF1 ORF (EBV-eGFP) (Maruo et al., 2001a; Nanbo et al., 2012, 2016). Akata- EBVeGFP cells were maintained in RPMI-1640 medium containing $10 \%$ FBS, antibiotics and $800 \mu \mathrm{g} / \mathrm{ml} \mathrm{G} 418$ (Wako Pure Chemical Industries Ltd., Osaka, Japan). Cells were maintained at $37^{\circ} \mathrm{C}$ in $5 \% \mathrm{CO}_{2}$. For induction of the lytic cycle of EBV, $\mathrm{Akata}^{+}$cells or $\mathrm{Akata}^{-}$EBV-eGFP cells were treated with $1 \%$ goat anti-human IgG (ahIgG; Dako, Glostrup, Denmark) (Takada, 1984; Takada and Ono, 1989).

\section{Electron Microscope}

Ultrathin-section electron microscopy was performed as previously reported (Noda et al., 2002, 2006). Briefly, 36 h after ahIgG treatment, Akata $^{-}$EBV-eGFP were washed with PBS and fixed with $2.5 \%$ glutaraldehyde in $0.1 \mathrm{M}$ cacodylate buffer $(\mathrm{pH}$ 7.4) for $1 \mathrm{~h}$ at $4^{\circ} \mathrm{C}$. Small pieces of fixed pellet were washed with the same buffer, post fixed with $2 \%$ osmium tetroxide in the same buffer for $1 \mathrm{~h}$ at $4^{\circ} \mathrm{C}$, dehydrated with a graded series of ethanol concentrations followed by propylene oxide, embedded in Epon 812 Resin mixture (TAAB Laboratories Equipment Ltd., Berks, 
England), and polymerized at $70^{\circ} \mathrm{C}$ for 2 days. Thin sections were stained with uranyl acetate and lead citrate and examined with a Hitachi H-7650 electron microscope (Hitachi Ltd., Japan) at $80 \mathrm{kV}$.

\section{Immunofluorescence Staining}

Akata $^{+}$cells $\left(2 \times 10^{6}\right.$ cells) were treated with $1 \% \alpha$ hIgG for $16 \mathrm{~h}$ in 6-well plate. The cells were fixed with $4 \%$ paraformaldehyde (PFA) in PBS for $10 \mathrm{~min}$ at room temperature (r.t.), permeabilized with PBS containing $0.05 \%$ Triton $\mathrm{X}-100$ for $10 \mathrm{~min}$ at r.t., and blocked in PBS containing $1 \%$ bovine serum albumin (BSA) for $20 \mathrm{~min}$ at r.t. The cells were incubated with mouse anti-EBV gp350/220 monoclonal antibody (clone C-1, 1:200 dilution) (Thorley-Lawson and Geilinger, 1980), goat anti-EBV p18 polyclonal antibody (Thermo Fisher Scientific, Waltham, MA, United States, 1:200 dilution), rabbit anti-TGN64 (Novus Biologicals, Littleton, CO, United States, 1:200 dilution), rabbit anti-GM130 monoclonal antibody (Cell Signaling Technology, clone D6B1, 1:200 dilution), rabbit anti-CD63 polyclonal antibody (Abcam, Cambridge, United Kingdom, 1:200 dilution), rabbit anti-Rab27a polyclonal antibody (Abcam, 1:200 dilution), or anti-Rab11 polyclonal antibody (Abcam, 1:200 dilution) for $1 \mathrm{~h}$ at r.t. After washing twice in PBS, the cells were incubated with Alexa Fluor 488, 594, or 647-labeled secondary antibodies (Thermo Fisher Scientific, 1:1000 dilution) for $1 \mathrm{~h}$ at room temperature. After washing twice in PBS, the nuclei were counterstained with Hoechst 33342 (Cell Signaling Technology, Beverly, MA, United States). Images were collected with a $60 \times$ water-immersion objective (NA $=1.3$ ) of a confocal laser scanning microscope (Fluoview FV10i, Olympus, Tokyo, Japan) and acquired by using FV10-ASW software (Olympus). Line scan imaging was performed by using FV10-ASW software.

\section{Western Blotting}

Induction of lytic cycle was confirmed by Western blotting by use of goat anti-EBV p18 polyclonal antibody (Thermo Fisher Scientific, 1:1000 dilution). The effect of induction of lytic cycle of EBV on the expression of organelle markers was analyzed by Western blot analysis with rabbit anti-TGN64 (1:500 dilution), rabbit anti-GM130 monoclonal antibody (1:1000 dilution), rabbit anti-CD63 polyclonal antibody (Wako pure chemical industries Ltd., 1:1000 dilution), mouse anti-Rab11 monoclonal antibody (BD Biosciences, San Jose, CA, United States, 1:1000 dilution), or rabbit anti-Rab27a polyclonal antibody (Sigma-Aldrich, 1:500 dilution).

\section{Brefeldin A Treatment}

For brefeldin A (BFA) treatment, 100 nM BFA (Cell Signaling Technology) was added to Akata $^{+}$cells $\left(5 \times 10^{5}\right.$ cells $)$ at $6 \mathrm{~h}$ post-induction of the lytic cycle. After $10 \mathrm{~h}$, the cells were harvested, and immunofluorescence staining was performed. To assess the effect of BFA on EBV egress, $100 \mathrm{nM}$ BFA was added to Akata $^{-}$eGFP-EBV cells at $6 \mathrm{~h}$ post-induction of the lytic cycle. Two days post-induction, the supernatants containing eGFP-EBV were harvested and incubated with Daudi ${ }^{-}$cells $\left(2 \times 10^{5}\right.$ cells $)$ in 24 -well plate for $1 \mathrm{~h}$ at $37^{\circ} \mathrm{C}$. After being washed the cells were incubated for $48 \mathrm{~h}$ later, the percentage of eGFP-positive infected cells was measured by flow cytometry (FACSCalibur, Becton, Dickinson and Company). The effect of BFA on the synthesis of EBV-encoded p18 was confirmed by Western blot analysis.

\section{RESULTS}

\section{EBV Capsids Acquire Their Primary Envelopment by Sequential Budding and Fusion Through the Perinuclear Cisterna}

To characterize the site for the final envelopment of EBV, the viral lytic cycle was induced by cross linking the cell surface IgG of $\mathrm{Akata}^{-}$EBV-eGFP by adding $\mathrm{F}(\mathrm{ab})_{2}$ fragments of goat anti-human IgG polyclonal antibody ( $\alpha$ hIgG) (Takada, 1984).

The cells were harvested after treatment with ahIgG for $36 \mathrm{~h}$ and the intracellular distribution of progeny virions were analyzed by electron microscopy. Consistent with previous reports, we observed multiple capsids containing the electron-dense cores inside in the nucleus of infected cells (Figures 1A vs. 1B). Capsids were frequently associated with less electron-dense materials than DNA cores (Figures 1B-D), which appeared to be replication compartments. We also observed a double-layered capsid without a core in the specimen (arrow in Figure 1C), which is likely a transient intermediate of capsid assembly.

We found that multiple irregular vesicles were formed in the cytoplasm in the lytically induced cells (Figures 1B, 2A). We also detected enveloped capsids in the perinuclear space between the INM and the ONM (Figure 2), suggesting that mature capsids bud into the perinuclear space to acquire a primary envelope. The envelopes were smooth without protrusions on their surface. In addition, the capsids that lack envelopes were distributed in the cytoplasm (Figures 2A, 3A-C), indicating that fusion between the primary envelopment and the ONM serves as a de-envelopment process, resulting in the release of capsids lacking envelope into the cytoplasm. These results confirmed the model that EBV acquires its primary envelopment by sequentially budding and fusion through the perinuclear cisterna as demonstrated previously (Seigneurin et al., 1977; Lee and Longnecker, 1997; Peng et al., 2010).

\section{EBV Capsids Acquire Tegument and Undergo a Final Envelopment in the Cytoplasm}

The cytoplasmic capsids were surrounded by electron-dense materials which appeared to be derived from tegument proteins (arrowheads in Figures 2B, 3A-C). This process occurred in the vicinity of cytoplasmic vesicles of various sizes that contained one or multiple enveloped capsids possessing tegument material. Spike-like protrusions attributable to glycoproteins were present on the envelopes. Vesicles containing mature virions were observed in the vicinity of the PM (Figure 3D). Several extracellular mature virions were observed in the peripheral region of the PM (Figure 4). They were composed of a bilayer 


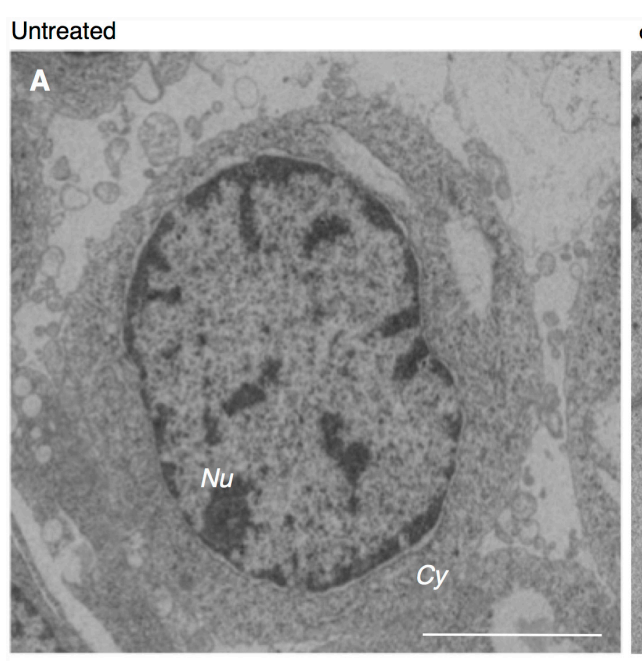

ahlgG-treated
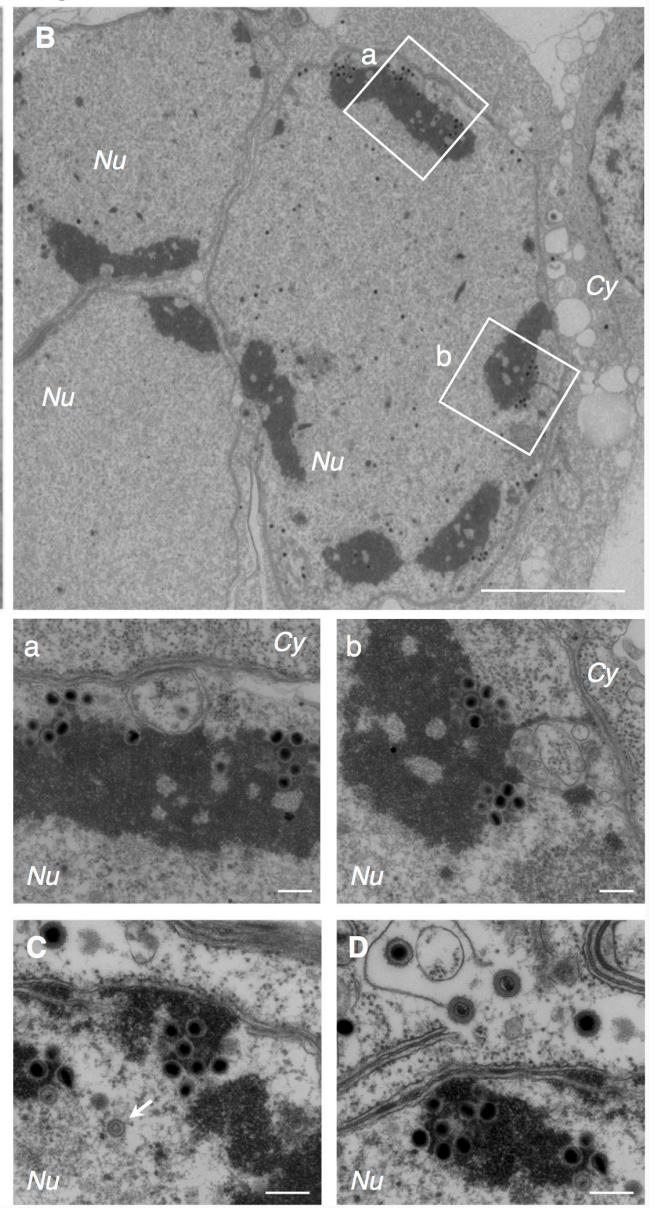

FIGURE 1 | Electron micrograph showing nucleocapsid formation in the nucleus of Akata cells induced into the lytic cycle of EBV. Morphological features of Burkitt's lymphoma cells induced lytic infection of EBV. Akata- eGFP-EBV cells were treated without (A) or with (B) $\alpha$ hlgG for 24 h. Low (A,B) and high (a,b,C,D) power views of Akata- eGFP-EBV cells. (a) and (b) represent boxed areas in (B). The white arrow indicates a double-layered capsid without core. Scale bars: $2.5 \mu \mathrm{m}$ (A,B) and $250 \mathrm{~nm}$ (a,b,C,D). In all the electron micrographs, italic abbreviations used for describing cellular compartments are as follows; Cy, cytoplasm; Nu, nucleus; Ve, vesicles; Ex, extracellular space; PM, plasma membrane; INM, inner nuclear membrane; ONM, outer nuclear membrane.

envelope with spikes, tegument materials in between bilayer envelope and a DNA core. All these results indicate that the egress of EBV likely take places via the exocytosis pathway, consistent with the model favored for other herpesviruses.

\section{EBV Structural Proteins Distribute in Compartments Containing Cis- and Trans-Golgi Markers}

Consistent with the notion of secondary envelopment of other herpesvirus subfamilies (Campadelli et al., 1993; Zhu et al., 1995; Das et al., 2007; Mori et al., 2008; Sugimoto et al., 2008; Cepeda et al., 2010; Hogue et al., 2014; Buckingham et al., 2016), EBV has been thought to exploit TGN- and endosome-derived vesicles to acquire its final envelopment. We observed that clathrin-coated vesicles, which originate from the Golgi complex (Robinson and Bonifacino, 2001), localized adjacent to the vesicles containing capsids (arrows in Figure 3C), although intact Golgi structures were not observed in the analyzed specimens.

We then characterized from which Golgi subcompartments EBV acquires its final envelope by immunofluorescence staining. We first assessed the distribution of one of major viral envelope glycoprotein, gp350/220 (Nemerow et al., 1987; Maruo et al., 2001b), which is expressed during the late phase of the lytic cycle, by immunofluorescence staining. At $16 \mathrm{~h}$ post-induction of the lytic cycle, gp350/220 distributed in the cytoplasm and the PM in a speckled pattern (green in Figure 5A). We further analyzed the distribution of TGN46, which is generally used as a marker of TGN. TGN46 distributed in the perinuclear region in mock-infected cells (Figure 5B). On the other hand, TGN46 localized in a dispersed pattern in the cells expressing gp350/220 and limited signals were observed (arrows in Figure 5A). Western blot analysis revealed that TGN46 expression was partly down-regulated in Akata cells treated with $\alpha$ hIgG (Figure 7). gp350/220 partly colocalized 

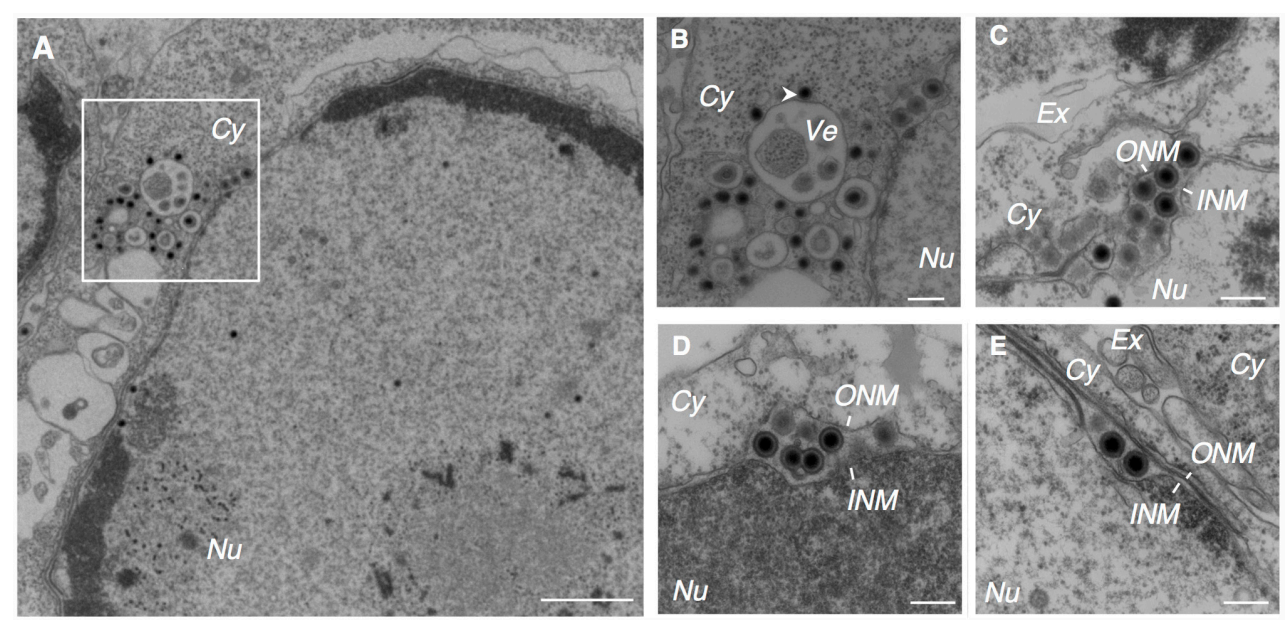

FIGURE 2 | EBV acquires its primary envelope by budding into the perinuclear space. Morphological features of Akata- eGFP-EBV cells induced into the lytic cycle showing primary envelopment and nuclear egress. Akata- ${ }^{-}$eGFP-EBV cells were treated with ahlgG for $24 \mathrm{~h}$. Low (A) and high (B-E) power views of Akata ${ }^{-}$ eGFP-EBV cells. (B) Represents boxed area in (A). The white arrowhead indicates high electron-dense material. Scale bars: $1 \mu \mathrm{m}$ (A) and $250 \mathrm{~nm}$ (B-E).
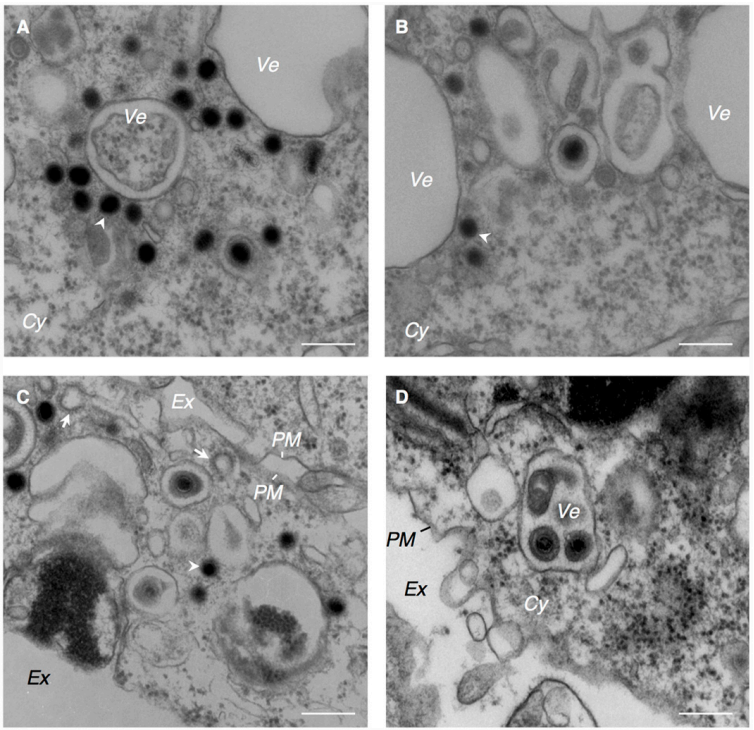

FIGURE 3 | EBV capsids acquire final envelopes in the cytoplasmic compartments. Morphological features of Akata- eGFP-EBV cells induced into lytic cycle showing acquisition of secondary envelope of EBV. Akata ${ }^{-}$eGFP-EBV cells were treated with ahlgG for $24 \mathrm{~h}$. High power views of Akata ${ }^{-}$eGFP-EBV cells (A-D). The white arrowheads indicate high electron-dense material. The white arrows indicate the clathrin-coated vesicles. Scale bars: $250 \mathrm{~nm}$.

with TGN46. We assessed the distribution of cis-Golgi marker, GM130 in the cells induced lytic cycle. As expected, GM130 distributed in the perinuclear region in mock-infected cells (Figure 5D). Unlike TGN46, the distribution of GM130 was largely unperturbed in gp350/220-positive cells (magenta in Figures 5C, 7). Moreover, gp350/220 (green) efficiently colocalized with GM130 signals (Figure 5C). To confirm
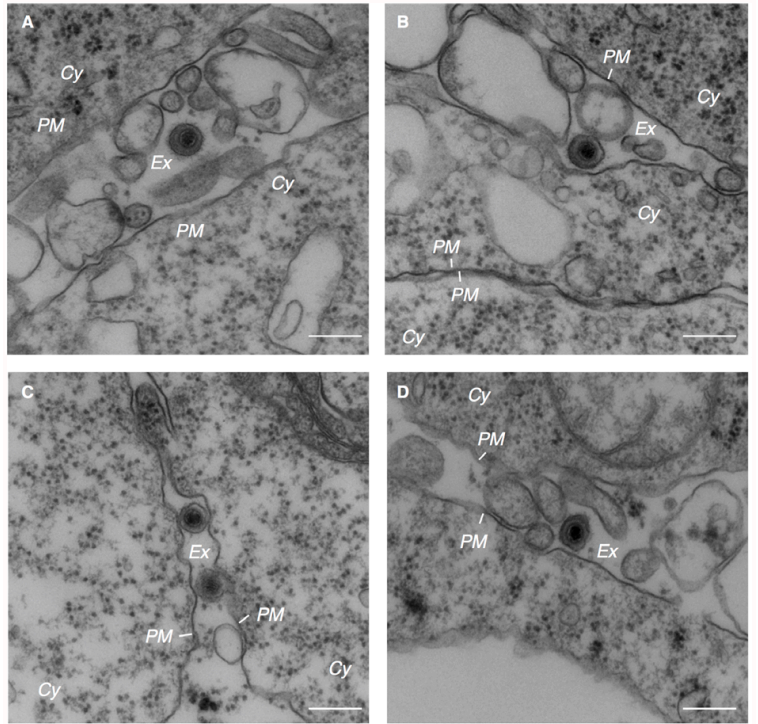

FIGURE 4 | Electron micrograph showing extracellular mature virions. Extracellular mature virions of EBV. Akata ${ }^{-}$eGFP-EBV cells were treated with ahlgG for $24 \mathrm{~h}$. High power views of Akata- eGFP-EBV cells (A-D).

Scale bars: $250 \mathrm{~nm}$.

that mature virions bud into the GM130-positive cellular compartments, we examined the distribution of GM130 and the EBV viral capsid antigen (VCA)-p18, BFRF3 (van Grunsven et al., 1994; Henson et al., 2009). VCA-p18 distributed in the nucleus diffusely, and in the cytoplasm and the PM in a speckled pattern (green in Figure 5E). GM130 efficiently colocalized with p18 in the cytoplasm and in the PM (magenta in Figure 5E). These results indicate that secondary envelopment of EBV takes place in the intracellular compartments containing cis- and TGN markers. 


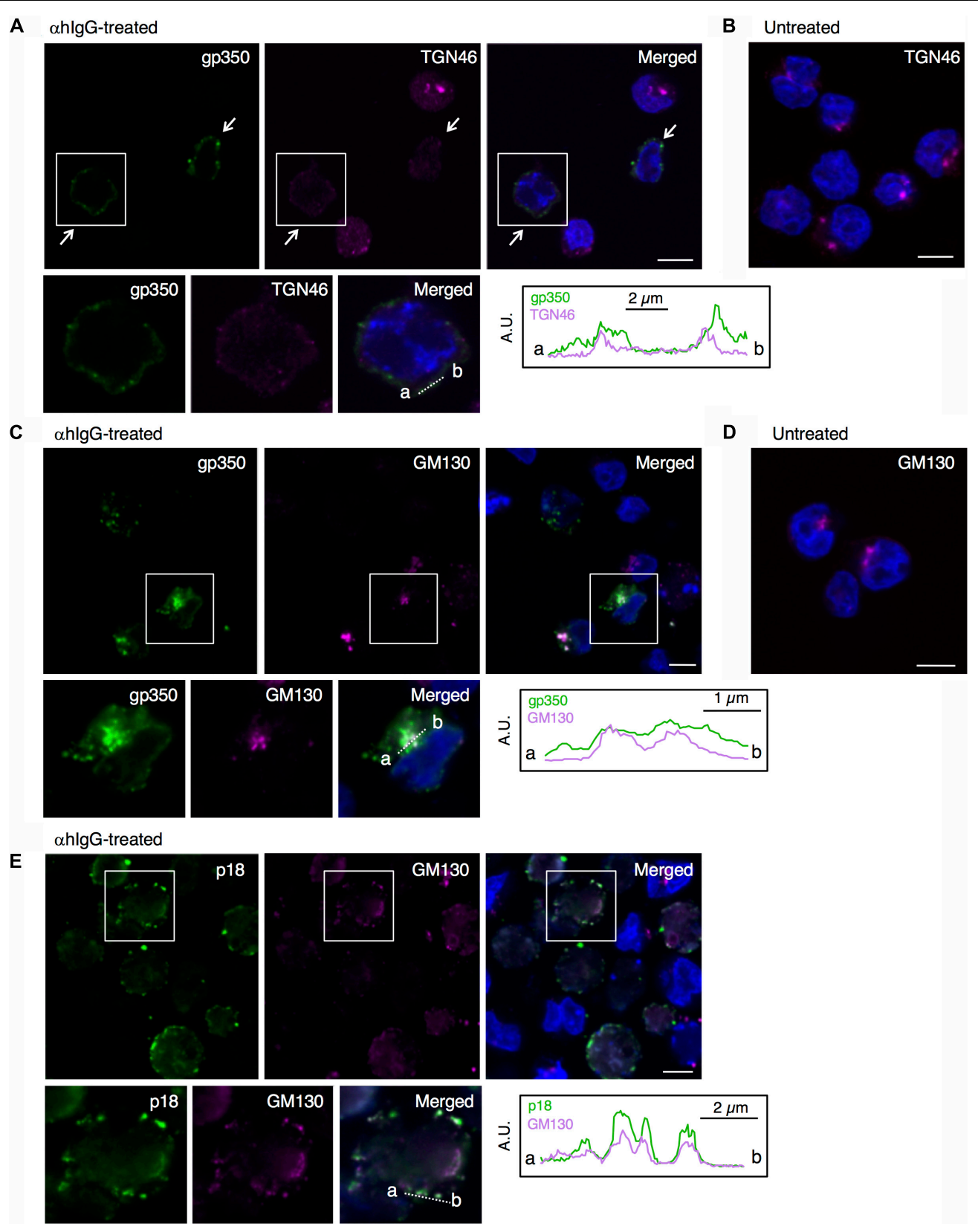

FIGURE 5 | EBV structural proteins distribute in the compartments containing cis-Golgi and the TGN markers. The distribution of the EBV structural proteins and markers of Golgi apparatus in Akata ${ }^{+}$cells induced into the lytic cycle. Akata ${ }^{+}$cells were treated with ahlgG (A,C,E) or without (B,D) for 16 h. (A) The distribution of gp350/220 (left), TGN64 (middle) and merged (right) images are shown. As a control, the distribution of TGN64 in the untreated cells is shown in (B).

(C) The distribution of gp350/220 (left), GM130 (middle) and merged (right) are shown. As a control, the distribution of GM130 in the untreated cells is shown in (D).

(E) The distribution of the EBV capsid antigen, p18 (left) and GM130 (middle) and merged (right) images are shown. The nuclei (blue) were counterstained with Hoechst 33342. Insets show the boxed areas. The plots indicate the individual fluorescence intensity along each of the corresponding lines. A.U., arbitrary unit. Scale bars: $10 \mu \mathrm{m}$.

\section{EBV Structural Proteins Do Not Colocalize With Secretory Endosomal Markers}

Because alphaherpesvirus and betaherpesvirus subfamilies acquire secondary envelopes by budding into the vesicles containing endosomal markers (Bloss and Sugden, 1994;
Wisner and Johnson, 2004; Das et al., 2007; Mori et al., 2008; Sugimoto et al., 2008; Cepeda et al., 2010; Hogue et al., 2014), we further investigated whether gp350/220 distributes in endosomes. We first examined the distribution of a marker for MVB, tetraspanin protein CD63 (van Niel et al., 2011). While CD63 distributes in the perinuclear region in control cells (Figure 6B), CD63 was visualized as speckles in the cells treated with ahIgG 
A ahlgG-treated
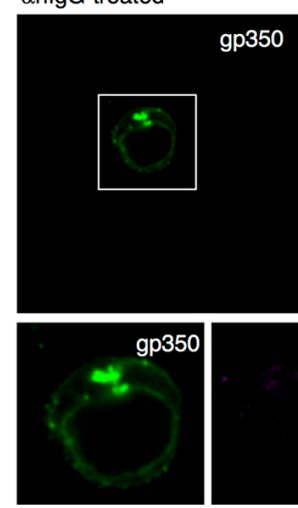

ahlgG-treated

C
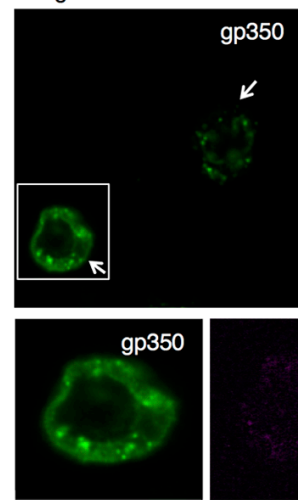

ahlgG-treated

E
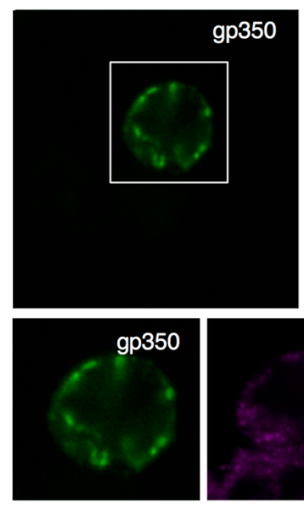
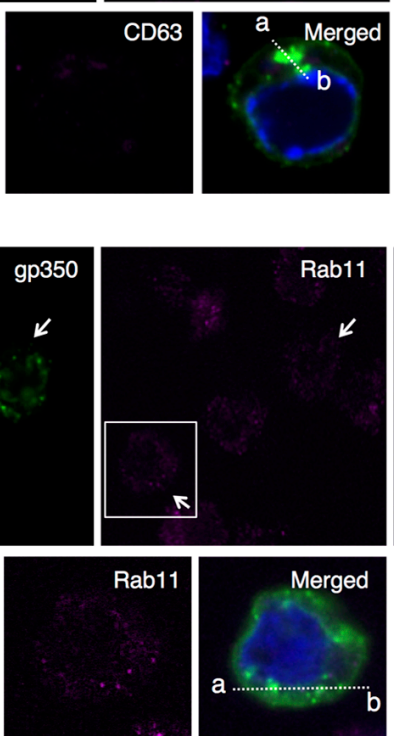

下

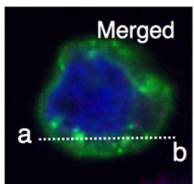

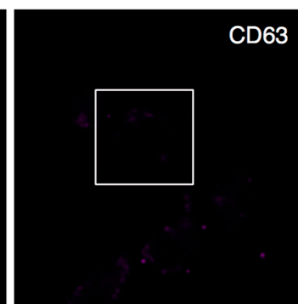

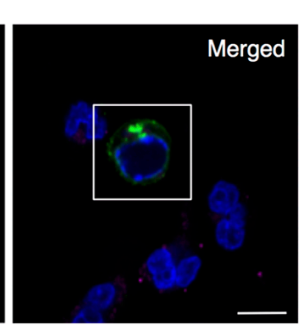

B Untreated
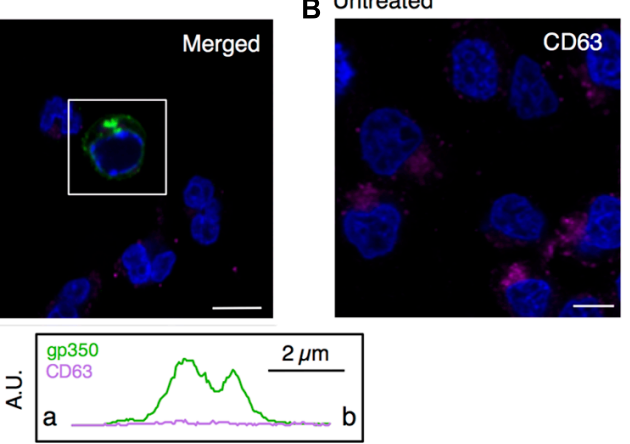

D Untreated
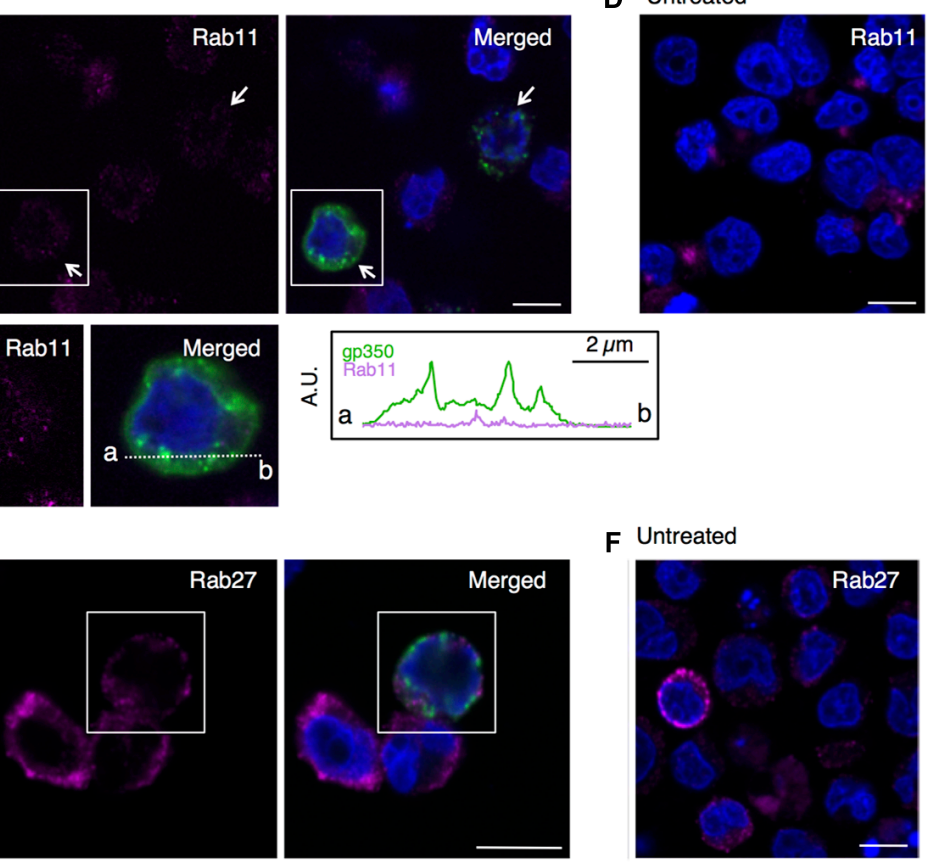

F Untreated
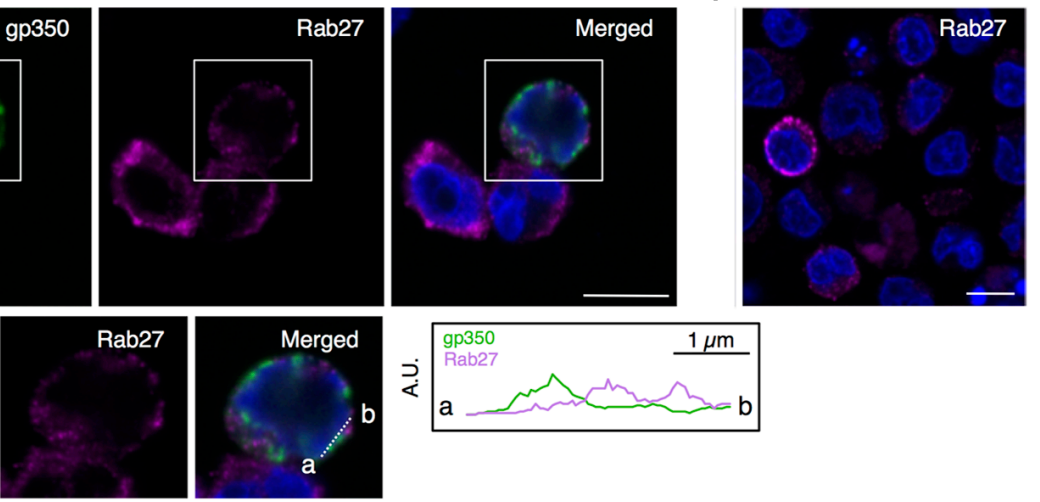

FIGURE 6 | EBV glycoprotein does not colocalize with endosomal markers. The distribution of the EBV glycoprotein and markers of endosomes in Akata ${ }^{+}$cells induced into the lytic cycle. Akata+ cells were treated with (A,C,E) or without ahlgG (B,D,F) for 16 h. (A) The distribution of gp350/220 (left), CD63 (middle) and merged (right) images are shown. As a control, the distribution of CD63 in the untreated cells is shown in (B). (C) The distribution of gp350/220 (left), Rab11 (middle) and merged (right) are shown. As a control, the distribution of Rab11 in the untreated cells is shown in (D). (E) The distribution of the EBV capsid antigen, gp350/220 (left) and Rab27a (middle) and merged (right) images are shown. As a control, the distribution of Rab27a in the untreated cells is shown in (F). The nuclei (blue) were counterstained with Hoechst 33342. Insets show the boxed areas. The plots indicate the individual fluorescence intensity along each of the corresponding lines. A.U., arbitrary unit. Scale bars: $10 \mu \mathrm{m}$.

(magenta in Figure 6A). gp350/220 (green) did not efficiently colocalized with CD63 signals (Figure 6A). We next assessed the role of recycling endosomes as a site for EBV maturation by use of a marker, Rab11 (Wilcke et al., 2000; Takahashi et al., 2012). Consistent with CD63, Rab11 was detected in the perinuclear region in untreated cells (Figure 6D). Upon induction of the lytic cycle, Rab11 signals (magenta) decreased and scattered in gp350/220-positive cells (arrows in Figure 6C). Down-regulation of Rab11 expression in ahIgG-treated Akata cells was also determined by Western blotting (Figure 7). No efficient colocalization was observed between Rab11 and gp350/220. Finally, we tested a small GTPase, Rab27a, which is associated with lysosome-related organelles (Neeft et al., 2005) and involved in regulation of the secretion pathway (Ostrowski et al., 2010; 


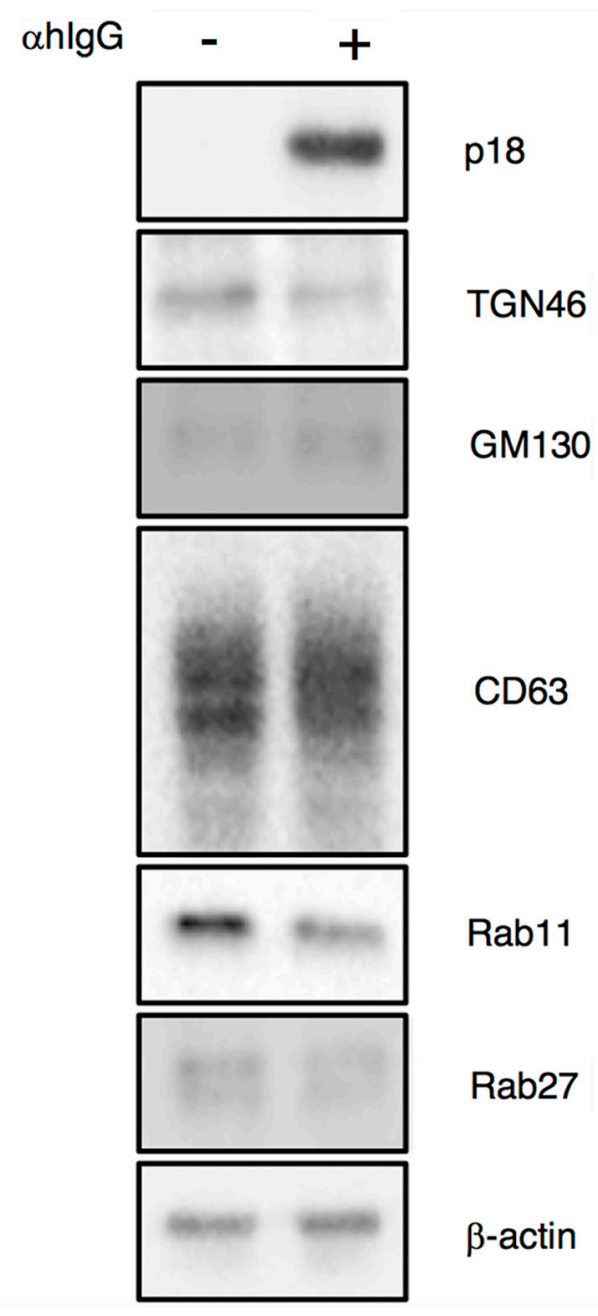

FIGURE 7 | Expression of organelle markers in Akata $^{+}$cells treated with ahlgG. Akata $^{+}$cells were treated with or without $\alpha$ hlgG for $16 \mathrm{~h}$. Total cell lysates were analyzed by Western blotting with antibodies against $p 18$, TGN46, GM130, CD63, Rab11, Rab27a, or $\beta$-actin.

Zografou et al., 2012). Rab27a distributed in a speckled pattern in the cytoplasm and its expression level was heterogeneous in the cell population (Figure 6F). We observed the gp350/220 (green) did not efficiently colocalize with the Rab27a-signal (magenta in Figure 6E). Taken together, it is unlikely that EBV capsids acquire the final envelope in endosomal compartments.

\section{Brefeldin A Treatment Induces the Intracellular Accumulation of EBV Glycoproteins}

We further assessed the role of the Golgi apparatus in the final envelopment of EBV by means of brefeldin A (BFA), a metabolite of the fungus Eupenicillium brefeldianum. BFA specifically and reversibly blocks protein transport from the ER to the Golgi apparatus (Lippincott-Schwartz et al., 1989; Pelham, 1991; Hunziker et al., 1992), resulting in a blockage of vesicular assembly, antigen presentation, transcytosis, endocytosis, and viral assembly and budding (Cheung et al., 1991; Whealy et al., 1991; Chatterjee and Sarkar, 1992). The lytic cycle was induced in the presence of $100 \mathrm{nM}$ BFA and the distribution of gp350/220 and cell organelle markers were analyzed by immunofluorescence staining. In contrast to untreated cells, treatment with BFA induced an accumulation of gp350/220 in the perinuclear region (green in Figures 8A-E). Furthermore, gp350/220 was not detectable in the PM. TGN46 distributed diffusely in $\alpha$ hIgG-treated cells in the presence of BFA and did not associate detectably with gp350/220 (Figure 8A). Signals from gp350/220 often colocalized with GM130 (Figure 8B). In contrast, gp350/220 did not colocalize with CD63, Rab11, and Rab27a (Figures 8C-E). These results indicate that BFA blocks transport of gp350/220 to the Golgi apparatus and its subsequent trafficking to the PM. We also measured the effect of BFA on the release of infectious virions. Akata- eGFP-EBV cells were induced into the lytic cycle in the presence of BFA. Two days post-induction, the supernatant containing eGFP-EBV was harvested and incubated with EBV-negative BL-derived Daudi ${ }^{-}$ cells. Forty-eight hours later, the percentage of eGFP-positive, infected cells was analyzed by flow cytometry. We found that BFA significantly inhibited the release of matured virions (Figure 8G). BFA treatment increased expression of p18 in the lytic cycle-induced cells (Figure $\mathbf{8 F}$ ), suggesting the intracellular accumulation of gp350/220. These results demonstrate that the final envelopment is established on the Golgi apparatus followed by egress though an unknown exocytotic machinery.

\section{DISCUSSION}

Accumulating evidence indicates that herpesvirus subfamilies likely share a mechanism for maturation and egress of their progeny virions (Johnson and Baines, 2011; Henaff et al., 2012). However, the mechanism underlying the acquisition of the final envelopment of gammaherpesvirus is poorly understood.

Previous studies characterized viral genes that are responsible for the primary envelopment of EBV. The EBV BGLF4 kinase modified the structure of nuclear lamina to initiate the egress of nucleocapsids (Gershburg et al., 2007; Lee et al., 2008). BFRF1 and BFLF2, which are highly conserved homologs among the herpesvirus family, have been shown to be involved in the nuclear egress of EBV. Moreover, BFRF1 exploits the host endosomal sorting complex required for transport (ESCRT) machinery to induce the reorganization of nuclear membrane followed by efficient nuclear egress (Gonnella et al., 2005; Lee et al., 2012). In contrast, the mechanism for final envelopment of EBV has remained unclear because of the lack of an efficient viral replication model.

Here, we characterized the sites for the final envelopment of EBV in BL-derived Akata cells induced into the lytic cycle by crosslinking cell surface IgG (Takada, 1984). Electron microscopic analysis visualized the formation of nucleocapsids in the nucleus (Figure 1), egress of enveloped nucleocapsids into the perinuclear space (Figure 2), release of cytoplasmic nucleocapsid lacking envelope (Figure 3), and irregular cytoplasmic vesicles 

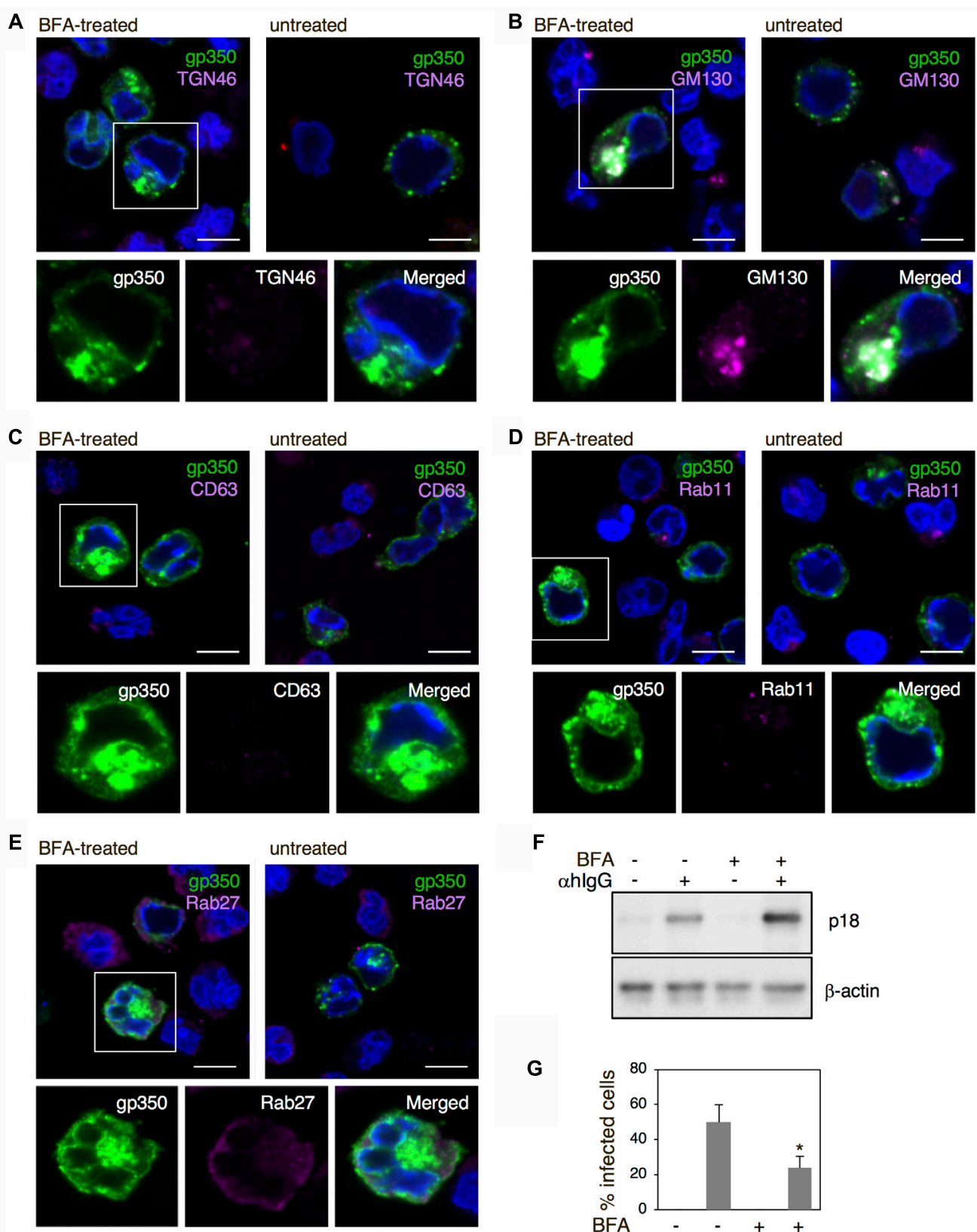

G

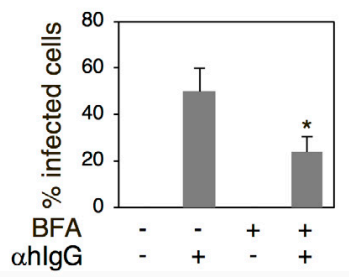

FIGURE 8 | The effect of BFA on the distribution of EBV structural proteins and the release of virions. (A-E) The effect of BFA on the distribution of gp350/220 and organelle markers in $\mathrm{Akata}^{+}$cells induced into the lytic cycle. Akata ${ }^{+}$cells were treated with ahlgG in the presence or absence of 100 nM BFA for 16 h.

The distribution of gp350/220 (green), TGN46 (A), GM130 (B), CD63 (C), Rab11 (D), and Rab27a (E) are shown. The nuclei were counterstained with Hoechst 33342. Insets show the boxed areas. Scale bars: $10 \mu \mathrm{m}$. (F) The effect of BFA on expression of p18 in Akata ${ }^{+}$cells undergoing the lytic cycle. Akata ${ }^{+}$cells were treated with or without $\alpha$ hlgG in the presence or absence of $100 \mathrm{nM}$ BFA for $16 \mathrm{~h}$. Total cell lysates were analyzed by Western blotting with antibodies against p18 or $\beta$-actin. (G) The effect of BFA on the release of virions. Akata- eGFP-EBV cells were treated with or without $\alpha$ hlgG in the presence or absence of 100 nM BFA for 48 h. Supernatants containing eGFP-EBV were harvested and incubated with Daudi- cells for 24 h. The percentages of eGFP-positive infected Daudi- cells were analyzed by means of flow cytometry. The experiment was performed three times independently and the average values and their standard deviations are shown for each condition. ${ }^{*} P<0.05$ versus respective control (Student's $t$-test).

containing mature virions (Figure 3). These results support a model in which EBV matures via a similar pathway to other herpesviruses, as previously thought (Johnson and Baines, 2011; Henaff et al., 2012).
We further characterized the origins of the vesicles in which mature viruses bud and found that Golgi apparatus markers such as GM130 and TGN46 colocalize with the viral major glycoprotein gp350/220 and the VCA p18 (Figures 5A,C,E), 


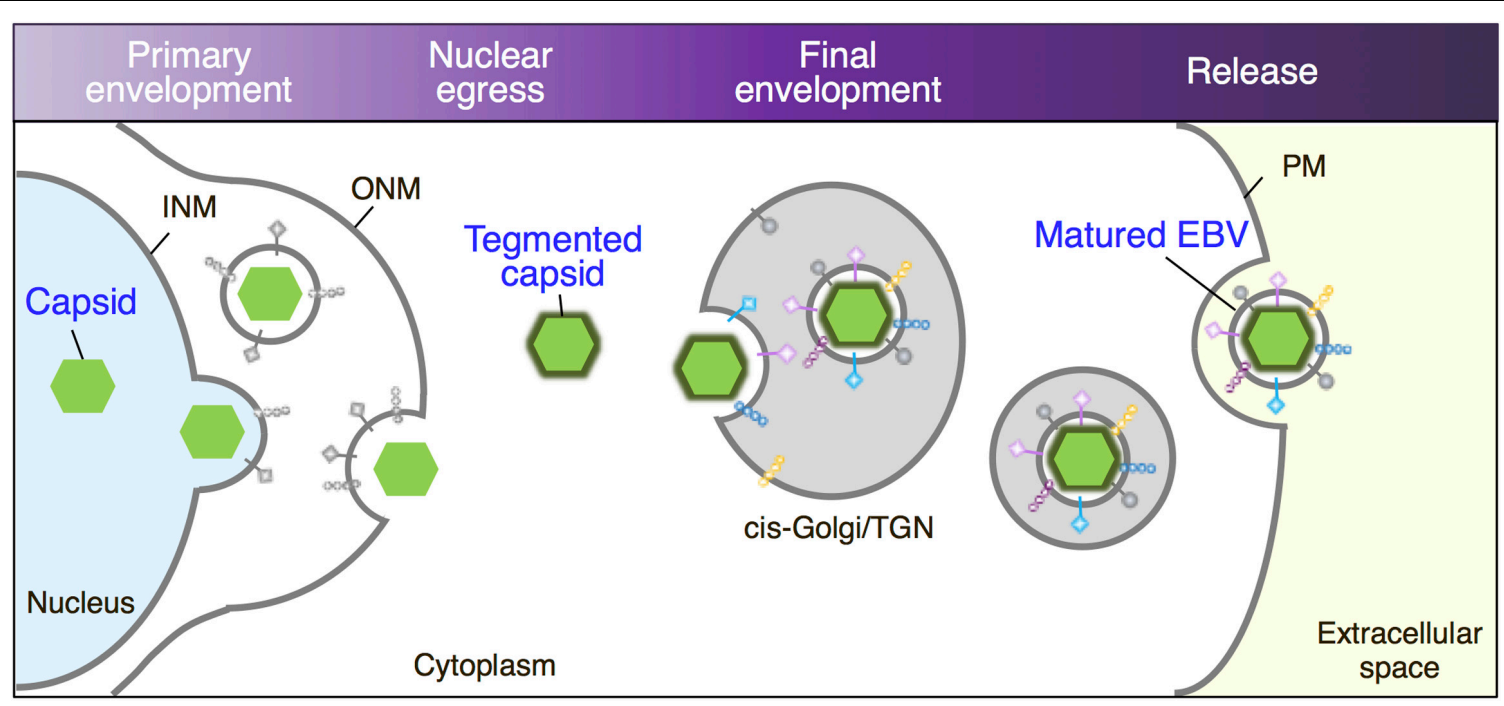

FIGURE 9 | Maturation of EBV virions. Replicated viral DNAs are packaged into capsids in the nucleoplasm. Nucleocapsids acquire primary envelopes by budding through the INM into the perinuclear space. Perinuclear enveloped virus particles undergo de-envelopment, which is mediated by membrane fusion between their primary envelope and the ONM (Nuclear egress). Tegument-coated nucleocapsids then undergo a final envelopment by budding into intracellular compartments derived from cis-Golgi/TGN, which produce mature virions in these compartments. Vesicles containing mature virions are then transported to the cell surface, fused with the PM to release virions into extracellular space.

suggesting that the final envelopment site for EBV originates from the Golgi apparatus as illustrated in Figure 9.

We often observed fragmented and dispersed TGN46 signals in the cytoplasm and periphery of the cells expressing EBV structural proteins (Figures 5A vs. 5B). HSV-1 infection also induces a similar distribution of TGN and endosomal compartments to the PM and cell-to-cell junctions, suggesting that it may reflect disruption of balanced bi-directional ER-Golgi transport induced by abnormal influx of viral glycoproteins and/or reorganization of TGN compartments to mediate virus egress by an exocytic pathway (Campadelli et al., 1993; Wisner and Johnson, 2004). In contrast, a limited alteration of the morphology and distribution of cis-Golgi was observed (Figures 5C vs. 5D). Since BFA treatment induced the accumulation of gp350/220 in the perinuclear region (Figure 8), EBV appears to target GM130-positive vesicles to provide the final envelopment, followed by subsequent trafficking through TGN to the PM for viral egress.

We observed that electron-dense materials were associated with cytoplasmic capsids lacking envelope in the vicinity of cytoplasmic vesicles (Figures 2, 3).

It has been shown that herpesvirus tegument proteins possess sorting signals for specific intracellular compartments, where the viral glycoproteins are loaded. The interaction between tegument proteins, membrane proteins, and glycoproteins in cytoplasmic compartments is crucial for the final envelopment (Johnson and Baines, 2011; Henaff et al., 2012). The distribution of limited tegument proteins has been revealed for $\mathrm{EBV}$.

BNRF1, the EBV major tegument protein, which is encoded only by members of the gammaherpesvirus subfamily, distributes both in the cytoplasm and nucleus (Tsai et al., 2011). While
BNRF1 has been shown to localize in PML nuclear bodies, its cytoplasmic distribution has not been studied in detail. Another tegument protein BBLF1, a homolog of UL11 for HSV-1 and UL99 for HCMV, has been shown to be involved in the final envelopment. Both endogenous and exogenously expressed BBLF1 are predominantly colocalized with TGN46. In contrast, overexpressed BBLF1 partially colocalized with GM130. BBLF1 did not colocalize with EEA1 and LAMP2, an early endosome and a late endosome marker, respectively (Chiu et al., 2012). Exogenously expressed BRRF2 gene, which is also conserved only in gammaherpesvirus subfamily members such as KSHV and MHV-68, partly localized with Rab5 but not with the ER and the Golgi apparatus markers (Watanabe et al., 2017). Because any inconsistency in the distribution of these tegument proteins might reflect the overexpression of protein alone, a further characterization of individual tegument proteins is essential in cells induced into EBV's lytic cycle.

Unlike alphaherpesviruses, betaherpesviruses are known to induce their own compartment containing various organelle markers (Tooze et al., 1993; Sanchez et al., 2000; Fraile-Ramos et al., 2002; Homman-Loudiyi et al., 2003; Das et al., 2007; Mori et al., 2008). We observed that irregularcytoplasmic vesicles are formed in lytically induced B cells (Figures 1B, 2A, 3), suggesting that EBV also reorganizes the pre-existing intracellular compartment to initiate secondary envelopment sites. A recent study has demonstrated that macroautophagic membranes are stabilized by the lytic cycle of EBV and macroautophagic proteins are incorporated into EBV virions (Nowag et al., 2014), suggesting that EBV exploits various cellular machinery for its efficient envelope acquisition. 
The vesicles containing mature EBV subsequently traffic to the PM and release virions extracellularly (Figure 4). In this study, viral structural proteins were not efficiently colocalized with endosomal markers, such as CD63, Rab11, and Rab27a, which are responsible for secondary envelopment and the egress of other herpesvirus subfamilies (Bloss and Sugden, 1994; Wisner and Johnson, 2004; Das et al., 2007; Mori et al., 2008; Sugimoto et al., 2008; Cepeda et al., 2010; Hogue et al., 2014). We found that signals of some organelle markers such as TGN46 and Rab11 decreased in the cells expressing viral lytic genes (Figures 5A, 6C, 7). In a previous study, mature EBV was found to incorporate viral and host proteins identified by tandem mass spectrometry (Johannsen et al., 2004). Limited organelle markers, such as clathrin-heavy chain and RablA were identified in these preparations. These findings indicate that the lytic cycle of EBV down-regulates expression of particular host genes, which may interfere with the analysis of EBV structural proteins colocalizing with organelle markers. To understand the detailed mechanism of EBV's maturation and egress, further investigations by use of alternative methods such as the immune electron microscopy and super resolution microscopy are required.

Taken together, our findings support a model in which EBV acquires its final envelope in intracellular compartments

\section{REFERENCES}

Bloss, T. A., and Sugden, B. (1994). Optimal lengths for DNAs encapsidated by Epstein-Barr virus. J. Virol. 68, 8217-8222.

Buckingham, E. M., Jarosinski, K. W., Jackson, W., Carpenter, J. E., and Grose, C. (2016). Exocytosis of Varicella-Zoster Virus virions involves a convergence of endosomal and Autophagy Pathways. J. Virol. 90, 8673-8685. doi: 10.1128/JVI. 00915-16

Campadelli, G., Brandimarti, R., Di Lazzaro, C., Ward, P. L., Roizman, B., and Torrisi, M. R. (1993). Fragmentation and dispersal of Golgi proteins and redistribution of glycoproteins and glycolipids processed through the Golgi apparatus after infection with herpes simplex virus 1. Proc. Natl. Acad. Sci. U.S.A. 90, 2798-2802.

Cepeda, V., Esteban, M., and Fraile-Ramos, A. (2010). Human cytomegalovirus final envelopment on membranes containing both trans-Golgi network and endosomal markers. Cell. Microbiol. 12, 386-404. doi: 10.1111/j.1462-5822. 2009.01405.x

Chatterjee, S., and Sarkar, S. (1992). Studies on endoplasmic reticulumGolgi complex cycling pathway in herpes simplex virus-infected and brefeldin A-treated human fibroblast cells. Virology 191, 327-337.

Cheung, P., Banfield, B. W., and Tufaro, F. (1991). Brefeldin A arrests the maturation and egress of herpes simplex virus particles during infection. J. Virol. 65, 1893-1904.

Chiu, Y. F., Sugden, B., Chang, P. J., Chen, L. W., Lin, Y. J., Lan, Y. C., et al. (2012). Characterization and intracellular trafficking of Epstein-Barr virus BBLF1, a protein involved in virion maturation. J. Virol. 86, 9647-9655. doi: 10.1128/JVI. 01126- 12

Das, S., Vasanji, A., and Pellett, P. E. (2007). Three-dimensional structure of the human cytomegalovirus cytoplasmic virion assembly complex includes a reoriented secretory apparatus. J. Virol. 81, 11861-11869.

Faggioni, A., Zompetta, C., Grimaldi, S., Barile, G., Frati, L., and Lazdins, J. (1986). Calcium modulation activates Epstein-Barr virus genome in latently infected cells. Science 232, 1554-1556. containing markers of Golgi apparatus. These findings provide new insights into our understanding of the mechanism of EBV's maturation.

\section{AUTHOR CONTRIBUTIONS}

AN was involved in conceptualizing the study, experimental design, and data analysis. AN and TN conducted the experiments. AN wrote the draft that was edited by TN and YO.

\section{FUNDING}

This work was supported by Japan Society for the Promotion of Science Grant Number 26460545, Takeda Science Foundation, SGH Foundation, Akiyama Life Science Foundation, and Shiseido Female Researcher Science Grant.

\section{ACKNOWLEDGMENTS}

We thank Dr. Bill Sugden (University of Wisconsin-Madison, Madison, WI, United States) for critically reviewing the manuscript.

Fraile-Ramos, A., Pelchen-Matthews, A., Kledal, T. N., Browne, H., Schwartz, T. W., and Marsh, M. (2002). Localization of HCMV UL33 and US27 in endocytic compartments and viral membranes. Traffic 3, 218-232.

Gershburg, E., Raffa, S., Torrisi, M. R., and Pagano, J. S. (2007). Epstein-Barr virus-encoded protein kinase (BGLF4) is involved in production of infectious virus. J. Virol. 81, 5407-5412.

Gershon, A. A., Sherman, D. L., Zhu, Z., Gabel, C. A., Ambron, R. T., and Gershon, M. D. (1994). Intracellular transport of newly synthesized varicella-zoster virus: final envelopment in the trans-Golgi network. J. Virol. 68, 6372-6390.

Gonnella, R., Farina, A., Santarelli, R., Raffa, S., Feederle, R., Bei, R., et al. (2005). Characterization and intracellular localization of the Epstein-Barr virus protein BFLF2: interactions with BFRF1 and with the nuclear lamina. J. Virol. 79, 3713-3727.

Granzow, H., Weiland, F., Jons, A., Klupp, B. G., Karger, A., and Mettenleiter, T. C. (1997). Ultrastructural analysis of the replication cycle of pseudorabies virus in cell culture: a reassessment. J. Virol. 71, 2072-2082.

Greenspan, J. S., Rabanus, J. P., Petersen, V., and Greenspan, D. (1989). Fine structure of EBV-infected keratinocytes in oral hairy leukoplakia. J. Oral Pathol. Med. 18, 565-572.

Hambleton, S., Gershon, M. D., and Gershon, A. A. (2004). The role of the trans-Golgi network in varicella zoster virus biology. Cell. Mol. Life Sci. 61, 3047-3056.

Hammerschmidt, W., and Sugden, B. (1988). Identification and characterization of oriLyt, a lytic origin of DNA replication of Epstein-Barr virus. Cell 55, 427-433.

Harley, C. A., Dasgupta, A., and Wilson, D. W. (2001). Characterization of herpes simplex virus-containing organelles by subcellular fractionation: role for organelle acidification in assembly of infectious particles. J. Virol. 75, 1236-1251.

Henaff, D., Radtke, K., and Lippe, R. (2012). Herpesviruses exploit several host compartments for envelopment. Traffic 13, 1443-1449. doi: 10.1111/j.16000854.2012.01399.x

Henson, B. W., Perkins, E. M., Cothran, J. E., and Desai, P. (2009). Self-assembly of Epstein-Barr virus capsids. J. Virol. 83, 3877-3890. doi: 10.1128/JVI.01733-08

Hogue, I. B., Bosse, J. B., Hu, J. R., Thiberge, S. Y., and Enquist, L. W. (2014). Cellular mechanisms of alpha Herpesvirus egress: live cell fluorescence 
microscopy of pseudorabies virus exocytosis. PLoS Pathog. 10:e1004535. doi: 10.1371/journal.ppat.1004535

Homman-Loudiyi, M., Hultenby, K., Britt, W., and Soderberg-Naucler, C. (2003). Envelopment of human cytomegalovirus occurs by budding into Golgi-derived vacuole compartments positive for $\mathrm{gB}$, Rab 3, trans-golgi network 46, and mannosidase II. J. Virol. 77, 3191-3203.

Hunziker, W., Whitney, J. A., and Mellman, I. (1992). Brefeldin A and the endocytic pathway. Possible implications for membrane traffic and sorting. FEBS Lett. 307, 93-96.

Johannsen, E., Luftig, M., Chase, M. R., Weicksel, S., Cahir-Mcfarland, E., Illanes, D., et al. (2004). Proteins of purified Epstein-Barr virus. Proc. Natl. Acad. Sci. U.S.A. 101, 16286-16291.

Johnson, D. C., and Baines, J. D. (2011). Herpesviruses remodel host membranes for virus egress. Nat. Rev. Microbiol. 9, 382-394. doi: 10.1038/nrmicro2559

Klein, E., Klein, G., Nadkarni, J. S., Nadkarni, J. J., Wigzell, H., and Clifford, P. (1968). Surface IgM-kappa specificity on a Burkitt lymphoma cell in vivo and in derived culture lines. Cancer Res. 28, 1300-1310.

Lake, C. M., and Hutt-Fletcher, L. M. (2000). Epstein-Barr virus that lacks glycoprotein $\mathrm{gN}$ is impaired in assembly and infection. J. Virol. 74, $11162-11172$.

Lee, C. P., Huang, Y. H., Lin, S. F., Chang, Y., Chang, Y. H., Takada, K., et al. (2008). Epstein-Barr virus BGLF4 kinase induces disassembly of the nuclear lamina to facilitate virion production. J. Virol. 82, 11913-11926. doi: 10.1128/JVI. 01100-08

Lee, C. P., Liu, P. T., Kung, H. N., Su, M. T., Chua, H. H., Chang, Y. H., et al. (2012). The ESCRT machinery is recruited by the viral BFRF1 protein to the nucleusassociated membrane for the maturation of Epstein-Barr Virus. PLoS Pathog. 8:e1002904. doi: 10.1371/journal.ppat.1002904

Lee, S. K., and Longnecker, R. (1997). The Epstein-Barr virus glycoprotein 110 carboxy-terminal tail domain is essential for lytic virus replication. J. Virol. 71, 4092-4097.

Lippincott-Schwartz, J., Yuan, L. C., Bonifacino, J. S., and Klausner, R. D. (1989). Rapid redistribution of Golgi proteins into the ER in cells treated with brefeldin A: evidence for membrane cycling from Golgi to ER. Cell 56, 801-813.

Longnecker, R., Kieff, E., and Cohen, J. I. (2013). “Epstein-Barr virus," in Fields Virology, 6th Edn, eds M. Knipe and P. M. Howley (Philadelphia, PA: Lippincott Williams \& Wilkins), 1898-1959.

Maruo, S., Nanbo, A., and Takada, K. (2001a). Replacement of the Epstein-Barr virus plasmid with the EBER plasmid in Burkitt's lymphoma cells. J. Virol. 75, 9977-9982.

Maruo, S., Yang, L., and Takada, K. (2001b). Roles of Epstein-Barr virus glycoproteins gp350 and gp25 in the infection of human epithelial cells. J. Gen. Virol. 82, 2373-2383.

Mori, Y., Koike, M., Moriishi, E., Kawabata, A., Tang, H., Oyaizu, H., et al. (2008). Human herpesvirus- 6 induces MVB formation, and virus egress occurs by an exosomal release pathway. Traffic 9, 1728-1742. doi: 10.1111/j.1600-0854.2008. 00796.x

Nanbo, A., Inoue, K., Adachi-Takasawa, K., and Takada, K. (2002). Epstein-Barr virus RNA confers resistance to interferon-alpha-induced apoptosis in Burkitt's lymphoma. EMBO J. 21, 954-965.

Nanbo, A., Kachi, K., Yoshiyama, H., and Ohba, Y. (2016). Epstein-Barr virus exploits host endocytic machinery for cell-to-cell viral transmission rather than a virological synapse. J. Gen. Virol. 97, 2989-3006. doi: 10.1099/jgv.0.00 0605

Nanbo, A., Kawanishi, E., Yoshida, R., and Yoshiyama, H. (2013). Exosomes derived from Epstein-Barr virus-infected cells are internalized via caveoladependent endocytosis and promote phenotypic modulation in target cells. J. Virol. 87, 10334-10347. doi: 10.1128/JVI.01310-13

Nanbo, A., Sugden, A., and Sugden, B. (2007). The coupling of synthesis and partitioning of EBV's plasmid Replicon is revealed in live cells. EMBO J. 26, 4252-4262.

Nanbo, A., Terada, H., Kachi, K., Takada, K., and Matsuda, T. (2012). Roles of cell signaling pathways in cell-to-cell contact-mediated EpsteinBarr virus transmission. J. Virol. 86, 9285-9296. doi: 10.1128/JVI. 00712-12

Neeft, M., Wieffer, M., De Jong, A. S., Negroiu, G., Metz, C. H., Van Loon, A., et al. (2005). Munc13-4 is an effector of rab27a and controls secretion of lysosomes in hematopoietic cells. Mol. Biol. Cell 16, 731-741.
Nemerow, G. R., Mold, C., Schwend, V. K., Tollefson, V., and Cooper, N. R. (1987). Identification of gp350 as the viral glycoprotein mediating attachment of Epstein-Barr virus (EBV) to the EBV/C3d receptor of B cells: sequence homology of gp350 and C3 complement fragment C3d. J. Virol. 61, 1416-1420.

Noda, T., Ebihara, H., Muramoto, Y., Fujii, K., Takada, A., Sagara, H., et al. (2006). Assembly and budding of Ebolavirus. PLoS Pathog. 2:e99. doi: 10.1371/journal. ppat.0020099

Noda, T., Sagara, H., Suzuki, E., Takada, A., Kida, H., and Kawaoka, Y. (2002). Ebola virus VP40 drives the formation of virus-like filamentous particles along with GP. J. Virol. 76, 4855-4865.

Nowag, H., Guhl, B., Thriene, K., Romao, S., Ziegler, U., Dengjel, J., et al. (2014). Macroautophagy proteins assist Epstein Barr Virus production and get incorporated into the virus particles. EBioMedicine 1, 116-125. doi: 10.1016/j. ebiom.2014.11.007

Orenstein, J. M., Alkan, S., Blauvelt, A., Jeang, K. T., Weinstein, M. D., Ganem, D., et al. (1997). Visualization of human herpesvirus type 8 in Kaposi's sarcoma by light and transmission electron microscopy. AIDS 11, F35-F45.

Ostrowski, M., Carmo, N. B., Krumeich, S., Fanget, I., Raposo, G., Savina, A., et al. (2010). Rab27a and Rab27b control different steps of the exosome secretion pathway. Nat. Cell Biol. 12, 19-30. doi: 10.1038/ncb2000

Pelham, H. R. (1991). Multiple targets for brefeldin A. Cell 67, 449-451.

Peng, L., Ryazantsev, S., Sun, R., and Zhou, Z. H. (2010). Three-dimensional visualization of gammaherpesvirus life cycle in host cells by electron tomography. Structure 18, 47-58. doi: 10.1016/j.str.2009.10.017

Robinson, M. S., and Bonifacino, J. S. (2001). Adaptor-related proteins. Curr. Opin. Cell Biol. 13, 444-453.

Sanchez, V., Greis, K. D., Sztul, E., and Britt, W. J. (2000). Accumulation of virion tegument and envelope proteins in a stable cytoplasmic compartment during human cytomegalovirus replication: characterization of a potential site of virus assembly. J. Virol. 74, 975-986.

Seigneurin, J. M., Vuillaume, M., Lenoir, G., and De-The, G. (1977). Replication of Epstein-Barr virus: ultrastructural and immunofluorescent studies of P3HR1superinfected Raji cells. J. Virol. 24, 836-845.

Shimizu, N., Tanabe-Tochikura, A., Kuroiwa, Y., and Takada, K. (1994). Isolation of Epstein-Barr virus (EBV)-negative cell clones from the EBV-positive Burkitt's lymphoma (BL) line Akata: malignant phenotypes of BL cells are dependent on EBV. J. Virol. 68, 6069-6073.

Sugimoto, K., Uema, M., Sagara, H., Tanaka, M., Sata, T., Hashimoto, Y., et al. (2008). Simultaneous tracking of capsid, tegument, and envelope protein localization in living cells infected with triply fluorescent herpes simplex virus 1. J. Virol. 82, 5198-5211. doi: 10.1128/JVI.02681-07

Takada, K. (1984). Cross-linking of cell surface immunoglobulins induces Epstein-Barr virus in Burkitt lymphoma lines. Int. J. Cancer 33, 27-32.

Takada, K., Horinouchi, K., Ono, Y., Aya, T., Osato, T., Takahashi, M., et al. (1991). An Epstein-Barr virus-producer line Akata: establishment of the cell line and analysis of viral DNA. Virus Genes 5, 147-156.

Takada, K., and Ono, Y. (1989). Synchronous and sequential activation of latently infected Epstein-Barr virus genomes. J. Virol. 63, 445-449.

Takahashi, S., Kubo, K., Waguri, S., Yabashi, A., Shin, H. W., Katoh, Y., et al. (2012). Rab11 regulates exocytosis of recycling vesicles at the plasma membrane. J. Cell Sci. 125, 4049-4057. doi: 10.1242/jcs.102913

Thorley-Lawson, D. A., and Geilinger, K. (1980). Monoclonal antibodies against the major glycoprotein (gp350/220) of Epstein-Barr virus neutralize infectivity. Proc. Natl. Acad. Sci. U.S.A. 77, 5307-5311.

Tooze, J., Hollinshead, M., Reis, B., Radsak, K., and Kern, H. (1993). Progeny vaccinia and human cytomegalovirus particles utilize early endosomal cisternae for their envelopes. Eur. J. Cell Biol. 60, 163-178.

Tsai, K., Thikmyanova, N., Wojcechowskyj, J. A., Delecluse, H. J., and Lieberman, P. M. (2011). EBV tegument protein BNRF1 disrupts DAXX-ATRX to activate viral early gene transcription. PLoS Pathog. 7:e1002376. doi: 10.1371/journal. ppat. 1002376

van Grunsven, W. M., Spaan, W. J., and Middeldorp, J. M. (1994). Localization and diagnostic application of immunodominant domains of the BFRF3-encoded Epstein-Barr virus capsid protein. J. Infect. Dis. 170, 13-19.

van Niel, G., Charrin, S., Simoes, S., Romao, M., Rochin, L., Saftig, P., et al. (2011). The tetraspanin CD63 regulates ESCRT-independent and -dependent 
endosomal sorting during melanogenesis. Dev. Cell 21, 708-721. doi: 10.1016/j. devcel.2011.08.019

Watanabe, T., Sakaida, K., Yoshida, M., Masud, H., Sato, Y., Goshima, F., et al. (2017). The C-terminus of Epstein-Barr Virus BRRF2 Is required for its proper localization and efficient virus production. Front. Microbiol. 8:125. doi: 10.3389/ fmicb.2017.00125

Whealy, M. E., Card, J. P., Meade, R. P., Robbins, A. K., and Enquist, L. W. (1991). Effect of brefeldin A on alphaherpesvirus membrane protein glycosylation and virus egress. J. Virol. 65, 1066-1081.

Wilcke, M., Johannes, L., Galli, T., Mayau, V., Goud, B., and Salamero, J. (2000). Rab11 regulates the compartmentalization of early endosomes required for efficient transport from early endosomes to the trans-golgi network. J. Cell Biol. 151, 1207-1220.

Wisner, T. W., and Johnson, D. C. (2004). Redistribution of cellular and herpes simplex virus proteins from the trans-golgi network to cell junctions without enveloped capsids. J. Virol. 78, 11519-11535.

Yates, J. L., Camiolo, S. M., Ali, S., and Ying, A. (1996). Comparison of the EBNA1 proteins of Epstein-Barr virus and herpesvirus papio in sequence and function. Virology 222, 1-13.
Zhu, Z., Gershon, M. D., Hao, Y., Ambron, R. T., Gabel, C. A., and Gershon, A. A (1995). Envelopment of varicella-zoster virus: targeting of viral glycoproteins to the trans-Golgi network. J. Virol. 69, 7951-7959.

Zografou, S., Basagiannis, D., Papafotika, A., Shirakawa, R., Horiuchi, H., Auerbach, D., et al. (2012). A complete Rab screening reveals novel insights in Weibel-Palade body exocytosis. J. Cell Sci. 125, 4780-4790. doi: 10.1242/jcs. 104174

zur Hausen, H., and Fresen, K. O. (1978). Heterogeneity of Epstein-Barr virus derived from P3HR-1 cells. IARC Sci. Publ. 391-396.

Conflict of Interest Statement: The authors declare that the research was conducted in the absence of any commercial or financial relationships that could be construed as a potential conflict of interest.

Copyright (c) 2018 Nanbo, Noda and Ohba. This is an open-access article distributed under the terms of the Creative Commons Attribution License (CC BY). The use, distribution or reproduction in other forums is permitted, provided the original author(s) and the copyright owner are credited and that the original publication in this journal is cited, in accordance with accepted academic practice. No use, distribution or reproduction is permitted which does not comply with these terms. 